December, 2012

\title{
New Perspectives on Community-level Determinants of Homelessness
}

Thomas Byrne, University of Pennsylvania

Ellen Munley, University of Pennsylvania

Jamison D Fargo, Utah State University

Anne Elizabeth Montgomery, University of Pennsylvania

Dennis P Culhane, University of Pennsylvania, et al. 


\title{
NEW PERSPECTIVES ON COMMUNITY-LEVEL DETERMINANTS OF HOMELESSNESS
}

\author{
THOMAS BYRNE and ELLEN A. MUNLEY \\ U.S. Department of Veterans Affairs, National Center on \\ Homelessness Among Veterans; University of Pennsylvania
}

\author{
JAMISON D. FARGO \\ U.S. Department of Veterans Affairs, National Center on \\ Homelessness Among Veterans; Utah State University
}

\author{
ANN E. MONTGOMERY \\ and DENNIS P. CULHANE \\ U.S. Department of Veterans Affairs, National Center on \\ Homelessness Among Veterans; University of Pennsylvania
}

\begin{abstract}
Understanding the root causes of homelessness is important for developing effective solutions to the problem. This fact has not gone unnoticed by researchers, who have made numerous attempts to identify the underlying structural determinants of homelessness by modeling inter-community variation in the rate of homelessness as a function of community-level variables. Yet, prior studies in this area have a number of serious limitations, principally their reliance on methodologically flawed estimates of the size of the homeless population. The present study addresses this and other limitations by using newly available and more reliable estimates from the U.S. Department of Housing and Urban Development to model variation in the rate of homelessness across a large and diverse sample of communities throughout the United States. In doing so, this study builds on the analysis conducted by Lee, Price-Spratlen, and Kanan (2003), and its findings have implications for policy and future research.
\end{abstract}

$\mathbf{S}_{\mathrm{i}}$ ince its emergence as a "public problem" (Stern, 1984) in the 1980s, homelessness has become an entrenched phenomenon, posing a consistent challenge to policymakers, advocates, and service providers alike. According to the most recent estimates, on any given night in the United States, there are roughly 645,000 persons residing in homeless shelters or in unsheltered street locations. Over the course of a year, approximately 1.6 million persons, or about 1 in every 195 Americans - and 1 in every 25 persons living below the poverty threshold-experience homelessness (U.S. Department of Housing and Urban Development, 2011). The sheer scope of the problem as well as the myriad negative health, economic, and social outcomes linked to

Direct correspondence to: T. Byrne, National Center on Homelessness Among Veterans, 4100 Chester Avenue, Suite 201, Philadelphia, PA 19104.E-mail: byrnet@sp2.upenn.edu

JOURNAL OF URBAN AFFAIRS, Volume 00, Number 0, pages 1-19.

Copyright (C) 2012 Urban Affairs Association

All rights of reproduction in any form reserved.

ISSN: 0735-2166.

DOI: 10.1111/j.1467-9906.2012.00643.x 
homelessness (Burt, 2001; Hawkins \& Abrams, 2007; Hwang, 2001; Lee \& Farrell, 2003; Lee \& Greif, 2008; Wolitski, Kidder, \& Fenton, 2007; Zerger, 2002) underscore the need to develop and implement effective policies to prevent and end homelessness.

The emergence and persistence of contemporary homelessness has been accompanied by a proliferation of studies that seek to identify its causal mechanisms. One approach has been to identify explanations for the geographic variation in the prevalence of homelessness. Researchers have identified conditions that co-vary with levels of homelessness, and described these conditions as possible causal factors of homelessness at the neighborhood, city, metropolitan, and state levels.

The present study adds to the existing body of literature consisting of cross-sectional studies of geographic variation in homelessness rates by (a) using more recent and reliable estimates of the homeless population; (b) conducting the first analysis to date of community-level determinants of homelessness that includes both metropolitan and non-metropolitan communities; and (c) increasing the comparability of findings across studies.

Our specific objective is to replicate and extend the community-level model of homelessness examined by Lee, Price-Spratlen, and Kanan (2003). Our goal is to assess whether using more recent data and including a broader set of communities yields different, and potentially more robust, findings than Lee et al. (2003). Our findings have potential implications for the use of these data and sample of communities in future research and might shed new light on policy changes that could reduce rates of homelessness.

\section{Review of Previous Studies}

Research on geographic variation in homelessness emerged in the 1990s in response to the predominance of individual-level studies in the existing homeless literature. By their nature, individual-level studies focused on characteristics and conditions of individuals and households, and were based on theoretical models that conceptualized homelessness as a result of individuallevel factors as varied as adverse childhood experiences, disability, mental illness, substance abuse disorders, lack of social or human capital, a history of institutional involvement, and exogenous health and income shocks (Bassuk, Rubin, \& Lauriat, 1984; Calsyn \& Roades, 1994; Curtis, Corman, Noonan, \& Reichman, 2011; Hopper, Jost, Hay, Welber, \& Haugland, 1997; Jones, 1983; Koegel, Melamid, \& Burnam, 1995; Metraux, Roman, \& Cho, 2008; O’Flaherty, 2009; Shinn et al., 1998; Susser, Lin, \& Conover, 1991).

In contrast, structural models, which provide the basis for many community-level studies, portray macro-level trends such as decreases in the availability of affordable housing, labor market conditions, cutbacks in safety net spending, prevalence of disabilities, and demographic factors as the primary drivers of homelessness (Burt, 1991; Koegel, Burnam, \& Baumohl, 1996; Main, 1996; McChesney, 1990; O’Flaherty, 1995; Rossi, 1989; Wright \& Lam, 1987). Over time, research on determinants of homelessness has moved toward a general consensus that individual and structural explanations are not mutually exclusive, and theoretical models have been developed that integrate the two types of factors (Culhane Lee, \& Wachter, 1996; O'Flaherty, 2004). However, as a study of homelessness rates at the community level, this paper focuses on structural community-level determinants of homelessness.

Much of the previous research on geographic variation in homelessness shares a similar methodological approach: most studies model the rate of homelessness in a city (or metropolitan area, county, or state) as a function of a set of city-level (or metropolitan area, county, or state) factors. However, studies have tested a range of community-level factors as potentially important determinants of homelessness, and likewise, the specific measure of the rate of homelessness that 
has been used as the dependent variable has varied across studies. Table 1 provides a summary of prior studies, including their measures of homelessness and the community-level factors that they included as predictors of homelessness.

\section{Community-Level Determinants of Homelessness}

The set of community-level factors hypothesized to be associated with homelessness varies across studies, making it a challenge to synthesize this body of research. Some consistencies have emerged, but for many factors, their inclusion in studies has been too inconsistent to allow conclusions to be drawn. Lee et al. (2003) categorized the community-level factors that predict rates of homelessness into the following broad domains: housing market, economic conditions, demographic composition, safety net, climate, and transience. Each domain is described in more detail in the following sections.

\section{Housing Market Factors}

At least one housing market factor, including rent levels and rental vacancy rates, regulation on housing construction, or presence of rent control, was associated with homelessness rates in each of the reviewed studies. Many researchers have placed primary focus on the shortfall of available affordable housing, resulting from a mismatch among housing cost, housing availability, and household income (Burt, 1991; Koegel, Burnam, \& Baumohl, 1996; Main, 1996; McChesney, 1990; O’Flaherty, 1995; Rossi, 1989; Wright \& Lam, 1987).

A number of prior studies have consistently identified significant relationships between increased rent levels, decreased vacancy rates, and increased homelessness. The proportion of renter households in a community has been positively associated with homelessness, while vacancy rate has been negatively associated with homelessness. The most consistent housing market finding has been a significant positive relationship between increased rent level and homelessness (Bohanon, 1991; Early \& Olsen, 2002; Honig \& Filer, 1993; Lee et al., 2003; Quigley, 1990; Quigley \& Raphael, 2002; Quigley, Raphael, \& Smolensky, 2001; Troutman, Jackson, \& Ekelund, 1999).

\section{Economic Conditions}

Local economic conditions also play an important role in determining the level of housing affordability in an area. Individual-level studies have established that homelessness generally occurs among people who are very poor (Burt \& Cohen, 1989), suggesting that poverty rates as well as additional factors that impact a household's income should be included in predictive models of homelessness rates. Prior studies on the community-level determinants of homelessness have most frequently used poverty and unemployment rates as proxies for economic conditions, and both have been found in numerous studies to be positively associated with the rate of homelessness (Appelbaum, Dolny, Dreier, \& Gilderbloom, 1991; Bohanon, 1991; Burt, 1993; Early \& Olsen, 2002; Quigley, 1990; Quigley \& Raphael, 2002; Quigley et al., 2001; Troutman et al., 1999).

\section{Demographic Composition}

While there is compelling evidence from other areas of literature on homelessness that demographic characteristics affect risk of homelessness, studies of geographic variation in rates 


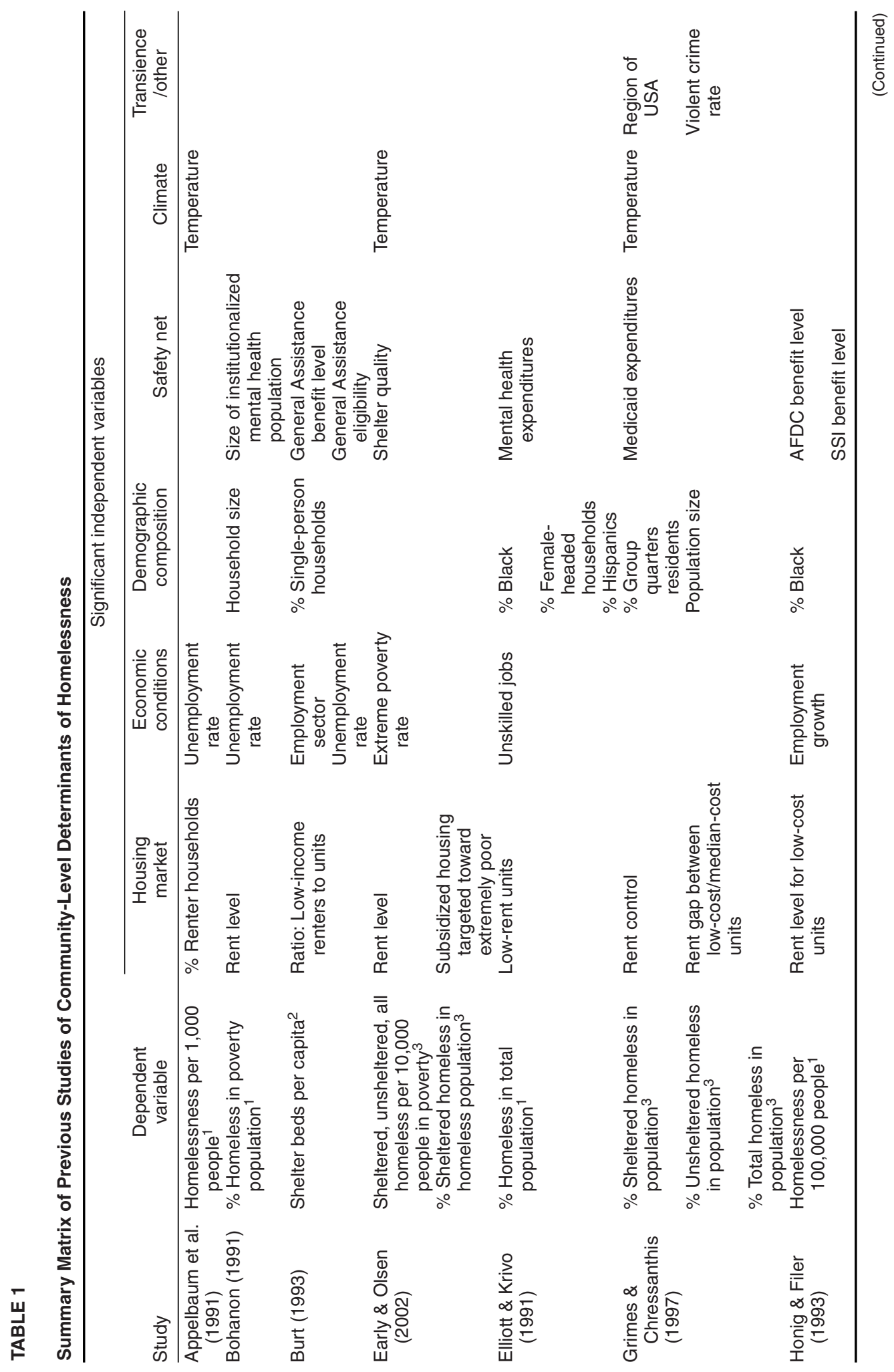




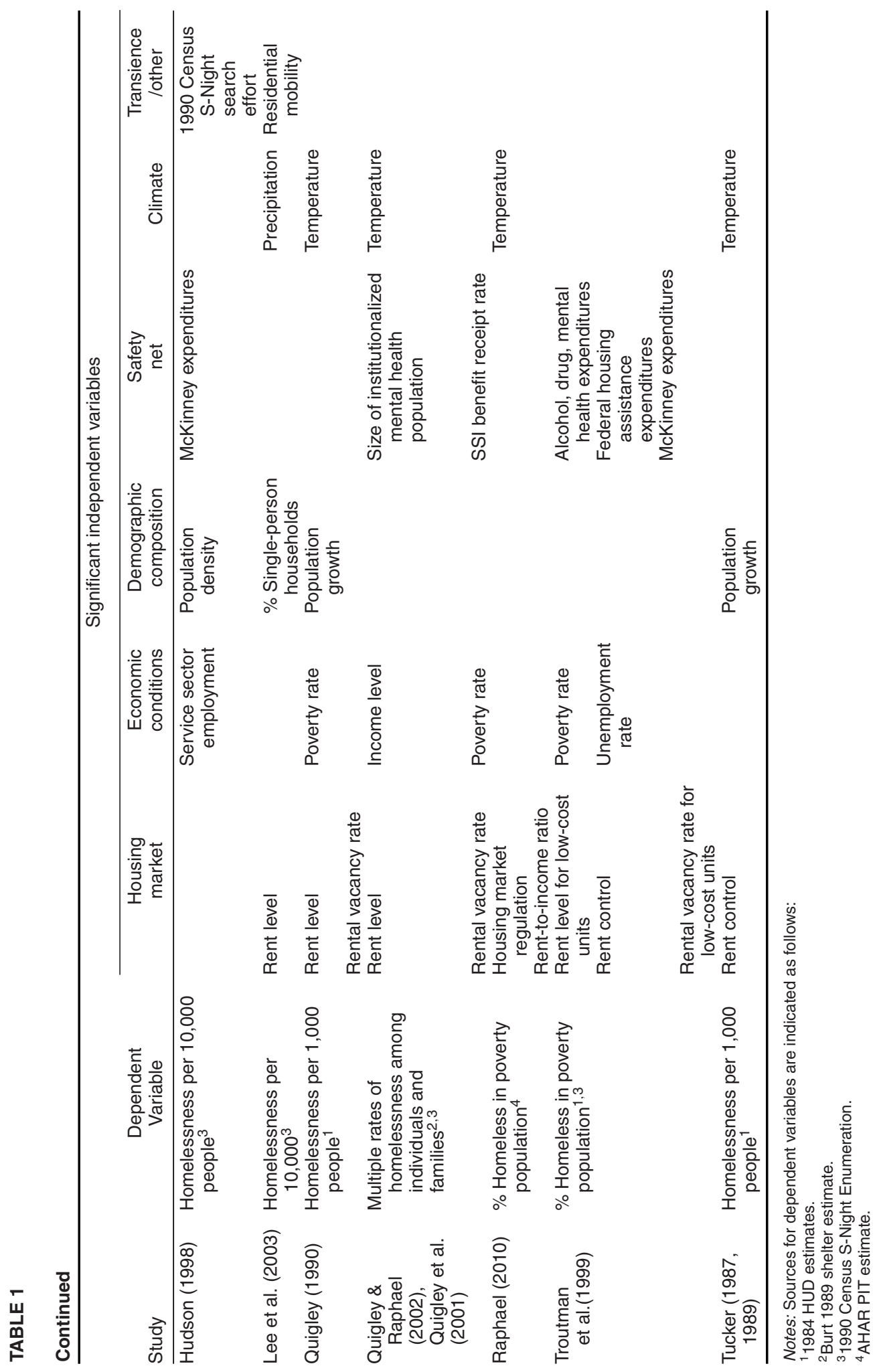


of homelessness have found inconsistent results for the relationship between variation in demographic composition of the population and variation in the rate of homelessness.

Cross-sectional studies have shown demographic characteristics, including race, to affect risk of homelessness among individuals. For example, African Americans have been consistently shown to be overrepresented in the homeless population (Burt, 2001; Culhane \& Metraux, 1999; U.S. Department of Housing and Urban Development [HUD] 2011); therefore, areas with higher proportions of African Americans may have higher rates of homelessness. In addition, evidence from a study of intra-city homelessness variation suggests that the proportion of female-headed households with young children is positively associated with homelessness (Culhane et al., 1996). Similarly, the concentration of single-person households in a community may be an important determinant of homelessness, both because single-person households cannot rely on the support of a second wage earner, thereby placing them at an increased risk of homelessness, and because communities with more single-person households may also face increased competition for lowcost rental units. Finally, the age distribution of the population in a particular community may affect the size of the homeless population, especially in light of evidence that members of the latter half of the baby-boomer age cohort-born between 1946 and 1964-make up a highly disproportionate share of the single adult homeless population (Culhane, Metraux, Byrne, Stino, $\&$ Bainbridge, in press).

Studies at the community level, in terms of the geographic variation in homelessness rates, have found also significant relationships between increased rates of homelessness and increased proportions of single-person and female-headed households (Burt, 1993; Elliott \& Krivo, 1991; Lee et al., 2003), African American households (Elliott \& Krivo, 1991; Honig \& Filer, 1993), and Hispanic households (Elliott \& Krivo, 1991). However, specific demographic measures have not been consistently shown to be significant across studies, and no study has found evidence of a relationship between a community's age distribution and its rate of homelessness.

\section{Safety Net}

Studies of homeless individuals have provided evidence that the size of the social safety net and the extent to which social safety net programs provide an adequate level of assistance can impact the chances that households will experience homelessness (Burt, 1991; Koegel et al., 1996; Rossi, 1989). Under this line of reasoning, more generous and more widely available safety net programs help protect low-income, disabled, and other vulnerable households from becoming homeless. For example, the degree to which income support programs like Temporary Assistance for Needy Families (TANF), Supplemental Security Income (SSI), or General Assistance (GA), are able to provide larger numbers of vulnerable households with resources adequate enough to help them obtain or maintain housing may impact the rate of homelessness. Similarly, increased spending on treatment programs and other services for persons with physical or mental disabilities, as well as for those with substance abuse disorders, who are all overrepresented in the homeless population, can provide households with supports that may keep them from becoming homeless.

However, because there are a variety of programs and ways to measure assistance, few studies have consistently included a single measure for a single program. Despite this lack of consistent results, studies have generally found that more extensive and more generous social safety net programs have a negative relationship with homelessness (Burt, 1993; Elliott \& Krivo, 1991; Honig \& Filer, 1993; Quigley \& Raphael, 2002; Quigley et al., 2001; Troutman et al., 1999).

\section{Climate}

Some studies attempting to explain geographic variation in homelessness have also added climate measures to models, hypothesizing that less precipitation or higher temperatures could 
contribute to higher measured rates of homelessness by making homeless people more visible, less vulnerable to mortality, or more likely to gravitate to a region. Among these studies, most have found climate to have a significant relationship with rates of homelessness, and in the expected direction, with higher temperatures and less precipitation associated with higher rates of homelessness, and higher proportions of persons experiencing homelessness in unsheltered locations (Appelbaum et al., 1991; Grimes \& Chressanthis, 1997; Lee et al., 2003; Quigley, 1990; Quigley \& Raphael, 2002; Quigley et al., 2001; Raphael, 2010; Tucker, 1987, 1989).

\section{Transience}

Lee et al. (2003) also examined transience as a possible determinant of homelessness, including the proportion of persons who have recently moved and the number of highways and railroads serving an area. The authors argue that areas with high residential mobility have more competitive housing and labor markets, which may increase the vulnerability to homelessness of those less well-suited to compete in these arenas. In addition, the extent to which an area is a frequent destination for tourists, migrant laborers, students, and others may have an impact on its rate of homelessness as some of these persons may wind up stranded and become homeless. Lee et al. find that the proportion of recently moved persons was a significant positive predictor, suggesting the importance of the relationship between the degree of residential mobility in an area and its rate of homelessness.

\section{Homelessness Dependent Variables}

The main challenge in executing studies that investigate determinants of the variation in the rate of homelessness across jurisdictions is obtaining accurate estimates of the number of persons experiencing homelessness in each location. Prior to 2005, few large-scale estimates of homelessness were available, and as such, the studies summarized in Table 1-with the exception of Raphael's 2010 study, which used state-level rates of homelessness from the 2007 Annual Homeless Assessment Report to Congress-have relied on one of three estimates of homelessness:

1. 1984 U.S. Department of Housing and Urban Development (HUD) estimate, based on a survey of local experts in 60 metropolitan areas, who reported the size of the homeless population in their area (HUD, 1984);

2. 1989 Burt survey of shelter capacity, covering 182 cities with populations greater than 100,000 (Burt, 1993); and

3. 1990 Census S-Night Enumeration, which was an effort by the Census Bureau to include more homeless people in the decennial census by counting homeless persons at emergency shelters and outdoor locations within municipalities with populations greater than 50,000 (U.S. Bureau of the Census, 1990).

Each of these efforts represented a methodological improvement over previously available data, but each also has flaws that may affect the reliability of findings from prior studies that have made use of these data. The primary methodological flaw with the 1984 HUD estimates was its sole reliance on informant interviews, which may have resulted in an undercount of the number of persons experiencing homelessness by applying estimates of homelessness in downtown areas to entire metropolitan areas (Appelbaum et al., 1991). Alternatively, the 1989 Burt survey used shelter bed capacity as a proxy for homelessness. This estimate did not account for unsheltered homelessness, turnover in shelter beds, and unused beds (Burt, 1993). The 1990 
Census S-Night Enumeration improved on these two studies by relying on actual enumeration of people experiencing homelessness. However, methodological flaws and inconsistency in how enumeration protocols were implemented across communities may have resulted in an undercount of the sheltered and unsheltered homeless population (Martin, 1992; U.S. General Accounting Office, 1991).

\section{Goals of the Current Study}

The sources of data used in this study further improve on past enumeration efforts. The biennial point-in-time count that HUD requires of communities nationwide enumerates sheltered homeless households using computerized systems that must meet a set of standard criteria to ensure accuracy in reporting (HUD, 2011). Enumeration of unsheltered households also must meet HUD's methodology standards (HUD, 2008). HUD has begun producing annual estimates based on enumerations that occur in a large number of communities of diverse size and urbanization. HUD's ongoing and extensive technical support to communities has resulted in marked improvement in the reliability of homeless counts over the past several years (HUD, 2011).

The current study will also expand the scope of geographic areas included in this type of research. By necessity, many prior studies restricted their sample sizes to a limited number of cities or metropolitan areas, due either to availability of estimates of the size of the homeless population, or due to a mismatch between geographies at which the independent variables (predictive factors) and dependent variables (rates of homelessness) were measured. This focus on larger urban areas is problematic given evidence that homelessness is shifting from principal cities to rural and suburban areas (HUD, 2011). The current study addresses this gap by conducting parallel analyses for separate samples of metropolitan and non-metropolitan communities. In doing so, it not only provides a more complete picture of structural determinants of homelessness, but also contributes to the body of knowledge on rural homelessness, a topic that has been excluded from most prior research.

The current study also aims to build on prior research by testing a set of potential structural determinants of homelessness that closely mirror those used by Lee et al. (2003), a rigorously designed study using homelessness data from the 1990 Census. The results from this study will be directly comparable to those reported by Lee and colleagues, allowing progress to be made towards more definitive identification of community-level factors that are the most important determinants of homelessness.

\section{METHODS}

\section{Data}

Our dependent variables were estimates of the number of persons experiencing homelessness in communities throughout the United States and our independent variables were characteristics of these communities along the six domains described previously.

\section{Dependent Variables (Homelessness)}

This study uses the HUD point-in-time (PIT) counts of unsheltered and sheltered homeless persons collected on a single night in January 2009 in 447 Continuums of Care (CoCs) throughout the United States. CoCs are geographic units at which providers of homelessness assistance share federal resources and work collaboratively to develop a strategic plan to address homelessness 
within their jurisdiction. CoCs vary in size and composition and can be comprised of single cities, individual counties, several counties, or entire states. Regardless of their size and composition, CoCs are geographically meaningful contexts for understanding the scope and determinants of homelessness since they are themselves spatial manifestations of how efforts to address homelessness are organized and administered. While 54 mainly rural counties are not part of a $\mathrm{CoC}$, more than $99 \%$ of the United States population lived within the boundaries of a CoC in 2009.

CoCs constitute the unit of analysis used in this study for assessing rates of homelessness. We use the HUD PIT estimates to construct two measures of the rate of homelessness, which parallel those used by Lee and colleagues: (1) the number of homeless adults per 10,000 adults in the general population, and (2) the number of homeless adults per 10,000 adults in poverty. We use homeless adults, which includes adults who are homeless as part of a family with children, rather than the overall number of persons experiencing homelessness as our numerator in constructing these rates to control for any potential variation in family size across CoCs. In addition, as persons experiencing homelessness are nearly universally poor, the second measure approximates the rate of homelessness among those who face the highest risk.

\section{Independent Variables (CoC and State Characteristics)}

To replicate the analysis conducted by Lee et al. (2003) as closely as possible, we collected independent variables mirroring those from a number of sources. These variables, their sources, and how they compare with the original variables used by Lee and colleagues are summarized in Table 2. The housing market measures (rent level, homeownership rate, vacancy rate), indicators of demographic composition (\% Black, \% Hispanic, \% baby boomers, $\%$ single-person households), and safety net measures (public assistance recipients, SSI recipients, TANF payment level, mental health expenditures) were almost identical to those used by Lee and colleagues. While several of the economic indicators-extreme poverty and unemployment-match Lee and colleagues', we were unable to include an indicator of low-wage jobs. Similarly, our transience measure was limited to mobility rate and excludes a variable for transport access. Finally, it was not feasible to include measures of climate given that $\mathrm{CoCs}$, which form our unit of analysis, can be large enough that there was significant within-CoC climate variation.

\section{Constructing the Research Dataset}

While the $\mathrm{CoC}$ was the unit of analysis for the homelessness dependent variables, $\mathrm{CoCs}$ constitute geographies with irregular boundaries. Consequently, measures of CoC-level characteristics (e.g., housing market and economic conditions) are virtually non-existent. As a result, we constructed $\mathrm{CoC}$-level independent variables from county-level measures using a two-step process. First, geospatial matching procedures linked all counties with their appropriate CoC. Second, county-level measures were statistically adjusted, where necessary, to transform them into $\mathrm{CoC}$-level variables. Given the irregular geographic composition of $\mathrm{CoCs}$, there were three relationship types possible between county and $\mathrm{CoC}$ boundaries:

1. Boundary for a single $\mathrm{CoC}$ and a single county was identical;

2. A single CoC may be comprised of an aggregation of two or more counties; and

3. Multiple CoCs may fall within a single county.

We used Geographic Information System (GIS) software to identify the appropriate CoCcounty relationship type for each $\mathrm{CoC}$ and, in turn, to match each $\mathrm{CoC}$ with its corresponding 


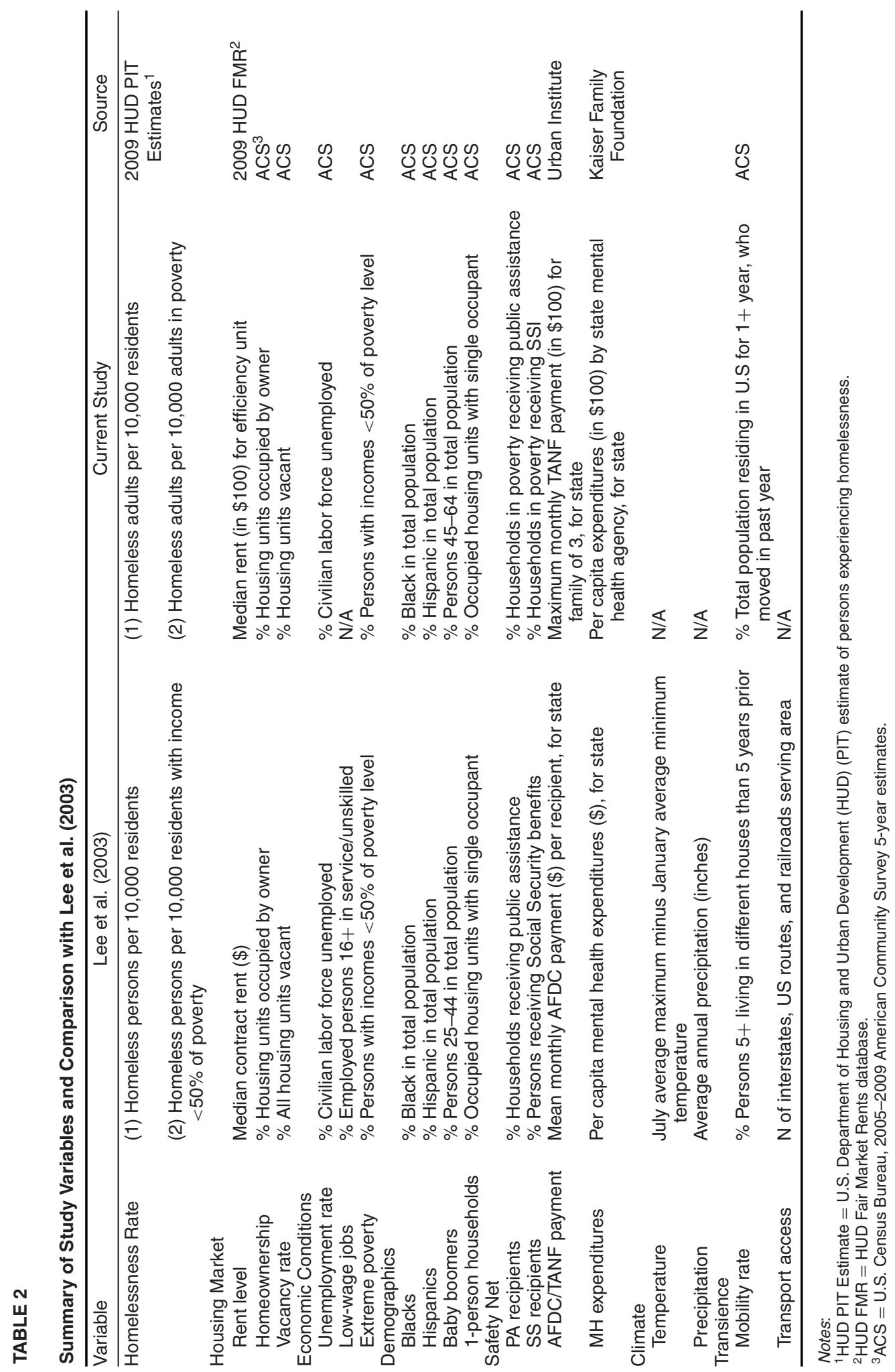


county or counties. To complete the matches, we superimposed county centroids (i.e., points representing the geographic center of counties) on a map of $\mathrm{CoC}$ boundaries. Approximately $51 \%(N=227)$ of CoCs matched directly to one county while $38 \%(N=171)$ of CoCs were comprised of multiple counties. The remaining $11 \%(N=49)$ of CoCs fit the third type of CoC-county relationship described earlier. In these cases, the multiple CoCs that were fully encompassed by a single county were merged into a single new $\mathrm{CoC}$, with its boundaries being coterminous with the county.

After appropriately matching CoCs and counties, we statistically adjusted the $171 \mathrm{CoCs}$ that fit the second type of relationship described above and the $49 \mathrm{CoCs}$ that fit the third type to complete the construction of CoC-level variables from county measures (no adjustments were necessary for the $227 \mathrm{CoCs}$ that met the criteria for the first type of relationship). In the case of the second type of relationship, we constructed CoC-level variables from county measures by taking either the sum or a population-weighted average of the county measures from all of the counties within a given $\mathrm{CoC}$. In the third type of relationship, where multiple CoCs within a single county were merged, we summed the HUD PIT estimates of persons experiencing homelessness from all of the CoCs located within a single county. In turn, county-level measures then became $\mathrm{CoC}$-level variables for these combined $\mathrm{CoCs}$, with no statistical adjustment required. The merging of several $\mathrm{CoCs}$ in this fashion resulted in a reduction in the number of $\mathrm{CoCs}$ from 447 to 414 , which we then stratified into metropolitan $(N=338)$ or non-metropolitan area $(N=76)$ groups using the U.S. Department of Agriculture's (USDA) Economic Research Service definitions of rurality (USDA, 2003).

Although the CoC was the basic unit of analysis for this study, several variables of interest (TANF payments, mental health expenditures) were only available at the state level. Variables measured at the state level were not adjusted and therefore all CoCs within a state assumed the same value.

\section{Statistical Analysis}

Because CoCs were nested within states, data from CoCs located within the same state were not considered to be independent from one another and are likely to have more similar characteristics than they would share with $\mathrm{CoCs}$ in different states. This clustering violates the basic assumption of independence in ordinary least squares (OLS) regression and such clustering must be accounted for in the statistical analysis to correctly model the variation in relationships between independent and dependent variables. Using a multilevel modeling approach rather than OLS regressions allowed us address this problem: we used the $\mathrm{CoC}$ as the first level of analysis and the state as the second level of analysis.

We conducted a series of linear mixed-effects models to understand which CoC variables were significantly associated with each homelessness outcome (homeless adults per 10,000 adults in the [a] general population and [b] population in poverty). OLS models were also estimated for each outcome, and had similar results to, but lower explanatory power than the linear mixed-effects models, and therefore are not reported here. In addition, we stratified the sample into metropolitan and non-metropolitan CoCs and conducted analyses separately for each subgroup. We applied a natural logarithmic transformation to each outcome variable due to their highly skewed natures. We included the following predictor variables in models with homeless adults per 10,000 adults in the general population: rent level; homeownership rate; housing vacancy rate; unemployment rate; extreme poverty rate; size of the Black, Hispanic, and baby boomer populations; public assistance recipients; SSI recipients; TANF benefit level; mental health expenditures; and mobility rate. With the exception of the percent of the population in extreme poverty, the same predictor variables 
were included in models where the population in poverty served as the denominator of the outcome.

Random intercepts were specified in all models. Analyses were conducted using the R environment for statistical computing (R Development Core Team, 2011). Due to difficulties inherent in calculating accurate confidence intervals and $p$-values for mixed-effects models, we calculated highest posterior density intervals and Monte Carlo derived $p$-values (Chen \& Shao, 1999), which are Bayesian analogues to these estimates.

\section{RESULTS}

Data were available for 414 CoCs (338 metropolitan, 76 non-metropolitan) and descriptive statistics for all study variables are presented in Table 3, stratified by metropolitan/nonmetropolitan status.

\section{Modeling Adult Homelessness per 10,000 Adults}

Several variables for models based on metropolitan and non-metropolitan samples were significantly associated with the rate of adult homelessness per 10,000 adults in the general population (see Table 4.) Although predictors in both metropolitan and non-metropolitan models accounted for a large degree of the variation in CoC homelessness rates $\left(R^{2}\right.$ for metropolitan $=58 \%$, nonmetropolitan $=67 \%$ ), notable differences were observed between models in terms of the pattern of significant predictors. For example, in the model for metropolitan CoCs, rent level, homeownership rate, the size of the Hispanic and baby-boomer populations, the proportion of single-person households, and the proportion of recently moved households were all positively associated with the outcome. In the model for non-metropolitan CoCs, however, rent level and unemployment rate were positively associated, and the size of the Black population was negatively associated with the outcome. The effects for rent level and the unemployment rate were particularly strong in the non-metropolitan CoC model, with a 32\% increase in homelessness per $\$ 100$ increase in median rent and a $27 \%$ increase in homelessness per $1 \%$ increase in unemployment.

\section{Modeling Adult Homelessness per 10,000 Adults in Poverty}

Similarly, several variables for models based on metropolitan and non-metropolitan samples were found to be significantly associated with the rate of adult homelessness per 10,000 adults in the population in poverty (see Table 5). The pattern of results was somewhat different between models based on metropolitan and non-metropolitan $\mathrm{CoCs}$, although the degree of variation in $\mathrm{CoC}$ homelessness rates accounted for by the independent variables was similar $\left(R^{2}\right.$ for metropolitan $=52 \%$, non-metropolitan $=56 \%$ ). In the metropolitan model, rent level, the size of the Hispanic and baby-boomer populations, the proportion of single-person households, rate of public assistance receipt, and mobility rate were positively associated and state mental health expenditures were negatively associated with the outcome. In contrast, in the non-metropolitan model, rent level was positively associated and the size of the Black population negatively associated with the rate of homelessness. The effect for rent level was particularly strong in both metropolitan and non-metropolitan CoC models, with a 15\% and 39\% increase in homelessness per $\$ 100$ increase in median rent, respectively. 


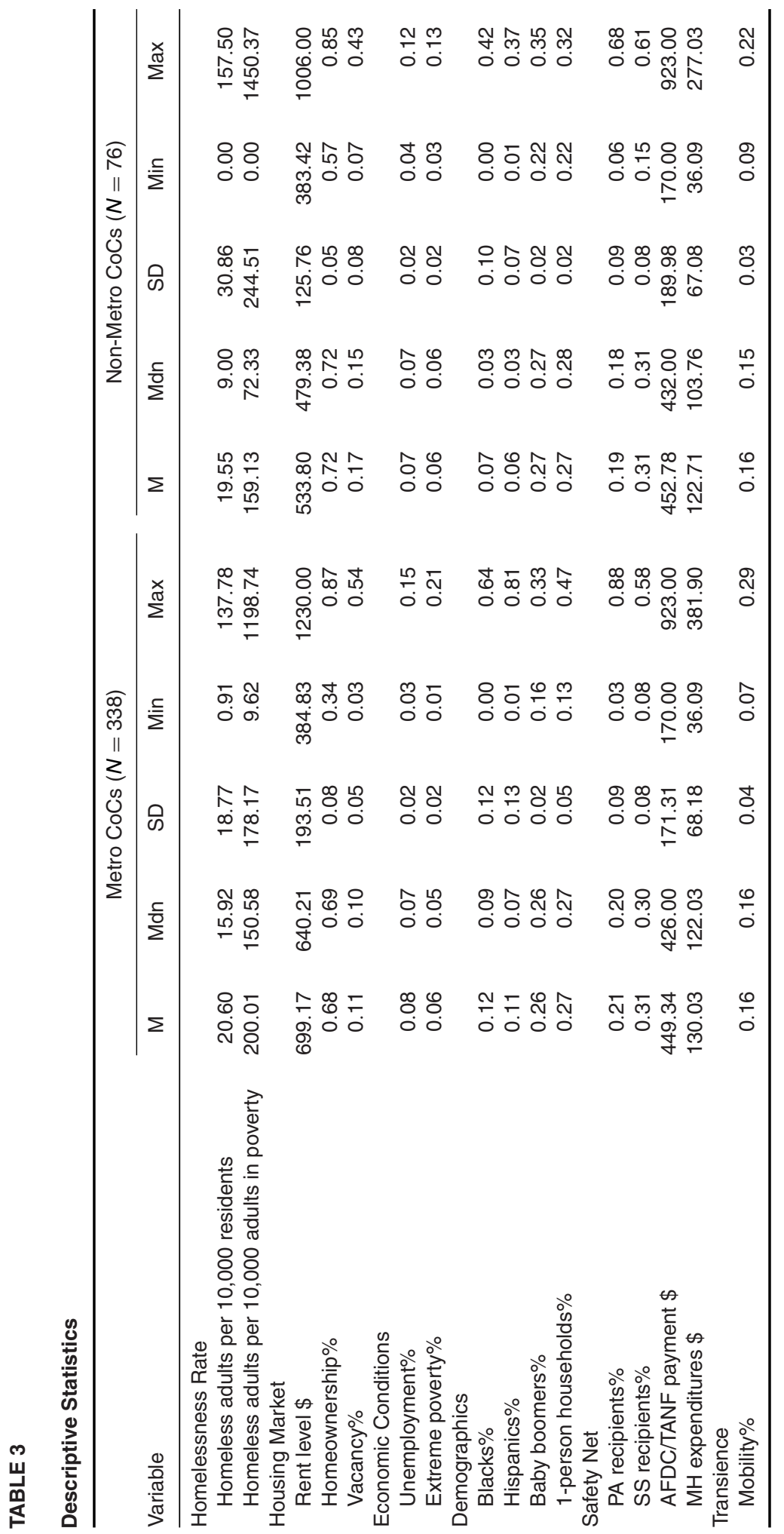


TABLE 4

Summary of Mixed-Effects Model for Variables Predicting Adult Homelessness per 10,000 Adults in General Population

\begin{tabular}{|c|c|c|c|c|c|c|}
\hline \multirow[b]{2}{*}{ Variable } & \multicolumn{3}{|c|}{ Metro CoCs $(N=338)$} & \multicolumn{3}{|c|}{ Non-Metro CoCs $(N=76)$} \\
\hline & $B$ & $95 \% \mathrm{Cl}$ & $p$ & $B$ & $95 \% \mathrm{Cl}$ & $P$ \\
\hline Intercept & -0.60 & $-2.80-1.50$ & 0.493 & 3.26 & $-5.70-11.38$ & 0.509 \\
\hline \multicolumn{7}{|l|}{ Housing Market } \\
\hline Rent level & 6.34 & 1.66-11.19 & 0.012 & 31.78 & $10.38-54.13$ & 0.005 \\
\hline Homeownership & -2.05 & $-3.75--0.68$ & 0.006 & -5.99 & $-12.92-0.38$ & 0.070 \\
\hline Vacancy rate & 0.18 & $-1.01-1.66$ & 0.677 & 0.96 & $-2.38-4.38$ & 0.575 \\
\hline \multicolumn{7}{|l|}{ Economic Conditions } \\
\hline Unemployment rate & 1.91 & $-2.65-8.02$ & 0.332 & 26.93 & $8.66-40.84$ & 0.004 \\
\hline Extreme poverty & 1.88 & $-3.23-6.53$ & 0.540 & -10.90 & $-28.63-10.22$ & 0.357 \\
\hline \multicolumn{7}{|l|}{ Demographics } \\
\hline Blacks & 0.07 & $-0.75-0.79$ & 0.944 & -4.15 & $-6.70--1.49$ & 0.002 \\
\hline Hispanics & 1.05 & $0.29-1.83$ & 0.006 & 1.68 & $-1.23-5.37$ & 0.210 \\
\hline Baby boomers & 7.43 & $3.63-12.20$ & $<0.001$ & 4.89 & $-8.26-21.08$ & 0.381 \\
\hline 1-person households & 3.58 & $1.01-5.37$ & 0.003 & 2.84 & $-8.38-15.20$ & 0.600 \\
\hline \multicolumn{7}{|l|}{ Safety Net } \\
\hline PA recipients & 1.05 & $-0.12-2.08$ & 0.080 & -3.41 & $-5.62-0.88$ & 0.153 \\
\hline SS recipients & 0.76 & $-0.42-1.96$ & 0.212 & -0.61 & $-3.66-2.73$ & 0.773 \\
\hline AFDC/TANF payment & -1.17 & $-8.41-6.63$ & 0.786 & -11.62 & $-36.20-6.51$ & 0.161 \\
\hline MH expenditures & -12.58 & $-28.82-2.13$ & 0.096 & 8.10 & $-52.24-51.87$ & 0.925 \\
\hline \multicolumn{7}{|l|}{ Transience } \\
\hline Mobility rate & 5.39 & $3.26-8.66$ & $<0.001$ & -1.77 & $-11.58-8.01$ & 0.739 \\
\hline SD Random Intercepts & & 0.25 & & & 0.35 & \\
\hline Model $R^{2}$ & & 0.58 & & & 0.67 & \\
\hline
\end{tabular}

\section{DISCUSSION}

The overarching objective of this study was to contribute to research on community-level structural determinants of homelessness by introducing new perspectives and directions to this body of research. On the whole, the use of HUD PIT data measuring homelessness rates has allowed us to confirm some findings of Lee and colleagues, while increasing the explanatory power of the model from $35 \%$ to $58 \%$. Our analysis also confirms their findings that rent level, single-person households, and recently moved households are positively associated with the rate of homelessness in the general population. While the significance of the public assistance receipt rate was not observed in our analysis, in both models a positive association was found for this variable. As a new contribution to this body of research, we found the homeownership rate to be negatively associated, and the size of the Hispanic population and babyboomer age cohort to be positively associated with the rate of homelessness among the general population.

Our results also confirmed findings of Lee and colleagues on the rate of homelessness among the population in poverty. Once again, rent level and the proportion of single-person households were confirmed to be positive and highly significant predictors of homelessness in metropolitan areas. In addition, we found the size of the Hispanic population and the baby-boomer cohort, as well as the proportion of recently moved households to be positively associated, and mental health expenditures to be negatively associated, with homelessness. One result contradicted the findings of the earlier study: both studies found the public assistance receipt rate to be a significant predictor, however, Lee and colleagues found it was negatively associated with the 
TABLE 5

Summary of Mixed-Effects Model for Variables Predicting Adult Homelessness per 10,000 Adults in Poverty

\begin{tabular}{|c|c|c|c|c|c|c|}
\hline \multirow[b]{2}{*}{ Variable } & \multicolumn{3}{|c|}{ Metro $\operatorname{CoCs}(N=338)$} & \multicolumn{3}{|c|}{ Non-Metro CoCs $(N=76)$} \\
\hline & B & $95 \% \mathrm{Cl}$ & $p$ & B & $95 \% \mathrm{Cl}$ & $p$ \\
\hline Intercept & -0.08 & $-2.57-1.90$ & 0.811 & -0.23 & $-9.87-9.06$ & 0.971 \\
\hline \multicolumn{7}{|l|}{ Housing market } \\
\hline Rent level & 14.53 & 9.96-20.17 & $<0.001$ & 39.19 & $12.26-65.71$ & 0.004 \\
\hline Homeownership & -0.46 & $-2.18-1.14$ & 0.570 & -1.32 & $-8.81-5.41$ & 0.622 \\
\hline Vacancy rate & -0.31 & $-1.80-1.12$ & 0.707 & 0.58 & $-3.64-4.46$ & 0.794 \\
\hline \multicolumn{7}{|l|}{ Economic conditions } \\
\hline Unemployment rate & -4.95 & $-9.65-1.31$ & 0.142 & 15.14 & $-1.84-31.58$ & 0.086 \\
\hline \multicolumn{7}{|l|}{ Demographics } \\
\hline Blacks & 0.17 & $-0.67-1.03$ & 0.768 & -3.99 & $-7.24--0.80$ & 0.014 \\
\hline Hispanics & 1.03 & 0.20-1.90 & 0.014 & 2.64 & $-1.14-6.94$ & 0.171 \\
\hline Baby boomers & 8.58 & $4.35-13.70$ & $<0.001$ & 10.92 & $-5.50-29.77$ & 0.173 \\
\hline 1-person households & 4.07 & $1.35-6.20$ & 0.001 & 2.14 & $-12.78-16.36$ & 0.752 \\
\hline \multicolumn{7}{|l|}{ Safety net } \\
\hline PA recipients & 2.13 & $0.94-3.21$ & $<0.001$ & -2.05 & $-5.01-2.47$ & 0.471 \\
\hline SS recipients & 1.12 & $-0.18-2.40$ & 0.104 & -0.64 & $-4.60-3.25$ & 0.757 \\
\hline AFDC/TANF payment & -1.58 & $-9.89-6.69$ & 0.718 & -6.61 & $-35.97-16.49$ & 0.487 \\
\hline $\mathrm{MH}$ expenditures & -19.57 & $-36.52--2.75$ & 0.024 & -8.12 & $-79.18-45.74$ & 0.592 \\
\hline \multicolumn{7}{|l|}{ Transience } \\
\hline Mobility rate & 5.61 & $3.18-9.18$ & $<0.001$ & -0.72 & $-12.34-11.94$ & 0.878 \\
\hline SD random intercepts & & 0.27 & & & & 0.29 \\
\hline Model $R^{2}$ & & 0.52 & & & & 0.56 \\
\hline
\end{tabular}

rate of homelessness among the poverty population while we found a positive association between these rates. Using the HUD PIT data increased the model's ability to explain overall variance in homelessness from $49 \%$ to $52 \%$.

Three primary points can be drawn from the results of our study. First, our findings provide additional evidence that homelessness has its roots in housing market dynamics, and particularly in the difficulty in obtaining affordable housing. Second, both of our metropolitan area models find the size of the baby-boomer cohort, the size of the Hispanic population, and the number of recently moved households to be positively associated with homelessness. Third, and finally, our study points to the great potential in using the newly available HUD PIT estimates of the homeless population to build on prior research and arrive at a better understanding of the structural determinants of homelessness.

Each of these key findings suggests the need for further study or policy changes. Our findings on the importance of affordable housing stock for decreasing homelessness underscore the need for policies that either increase the supply of affordable housing or provide additional safety net supports to households to help them afford housing and decrease competition for a finite number of low-rent units. Given the finding that rates of homelessness were higher in areas with relatively more single-person households, the need for additional safety net supports may be particularly acute for persons in this group who are especially vulnerable to homelessness in the event of job loss, illness, or other income shocks. While an expansion of the Section 8 Housing Choice Voucher Program, which is the primary federal housing assistance program for low-income families, would be the most straightforward remedy to the affordable housing problems that appear to be the most important drivers of homelessness, recent history and the 
current political and fiscal environment provide little reason to believe that such an expansion is likely to be forthcoming.

However, there are a number of pragmatic alternative options to a pure expansion of housing subsidies that might help address the prevailing lack of affordable housing. For example, Khadduri (2010) describes a plan for overhauling the Section 8 program such that subsidies are targeted more directly to those individuals and jurisdictions at highest risk of or with the highest rates of homelessness, thereby making it a more effective tool for preventing homelessness. Providing a tax credit to all low-income renters similar to the existing Earned Income Tax Credit (EITC), an idea proposed by Landis and McClure (2010), would also go far in helping those at risk of homelessness maintain housing. It would also serve as an important counterbalance to the mortgage interest deduction, which almost exclusively benefits middle- and upper-income Americans. Others have suggested that relaxing zoning requirements or other local regulations on housing construction might encourage the creation of more affordable housing units (Joint Center for Housing Studies at Harvard University, 2008). While these are just a sampling of the ideas that have been put forth as potential solutions to problems related to housing affordability, they underscore the potential effectiveness of creative housing policy reform.

Our findings on demographic groups and residential mobility merit closer attention, both in future research and from a policy standpoint. The finding regarding the baby-boomer age group is consistent with evidence that baby boomers are highly overrepresented in the homeless population, and underscores the need to develop targeted interventions to address homelessness among members of this population. Indeed, substantial reductions in the overall rate of homelessness could be achieved by targeting this demographic sub group. Here, housing subsidies that offer a more limited form of support than a full Section 8 voucher might be an especially viable approach, but additional research is needed to test the effectiveness of such "shallow" subsidies. The findings regarding Hispanic ethnicity and residential mobility suggest that migration patterns may have a more important relationship with the rate of homelessness than has been previously considered. Future research should delve more deeply into these issues, particularly the finding that rates of homelessness were higher in areas with relatively more Hispanics. This finding seems inconsistent with prior research showing Hispanics to be underrepresented in the homeless population, which has been credited largely to their greater propensity for relying on informal housing arrangements to avoid homelessness (Rosenheck, Bassuk, \& Salomon, 1999). One plausible interpretation of our finding that could be investigated by future studies is that the documented migration of Hispanics out of large cities and into smaller communities and rural areas (Kandel \& Cromartie, 2004), has strained their social and kinship networks, limiting their opportunities to rely on informal housing arrangements when needed.

Although this study made progress towards its objective, it also had a few limitations that bear mentioning. Similar to Lee and colleagues' study, the present study does not control for the capacity of homelessness assistance programs; therefore, our dependent variables may be conflated with the magnitude of a community's response to the problem. Even though this study applies rigorous methods to match the geography at which homelessness is measured to the geography at which structural factors are measured, the mismatch between the two continues to present problems in identifying important community-level influences on these rates; alternative methods to classify CoCs as urban or rural could yield different results.

While this is the first study to examine the structural determinants of homelessness using a set of non-urban jurisdictions, we have merely taken the first step in expanding this body of research. The HUD PIT estimates of homelessness used in this study are also available for a range of sub-populations of persons experiencing homelessness, including families, persons with serious mental illness, veterans, and persons experiencing chronic homelessness. It is likely that community-level determinants of homelessness may operate differently for each of these 
sub-populations, and this should be investigated in future research. Similarly, this study, by design, considered a fairly small set of factors as potential community-level determinants of homelessness; there is certainly room to expand research to include a wide range of additional measures, including those that have received less attention in the literature.

The results of this study demonstrate that the dynamics operating at the macro level are important for understanding homelessness and that, correspondingly, macro-level policy interventions are ultimately necessary to prevent and end homelessness. Future research that expands on this study and provides additional insight regarding structural factors that are important determinants of homelessness would be crucial for informing policy-level interventions.

\section{REFERENCES}

Appelbaum, R., Dolny, M., Dreier, P., \& Gilderbloom, J. (1991). Scapegoating rent control: Masking the causes of homelessness. Journal of the American Planning Association, 57, 153-164.

Bassuk, E. L., Rubin, L., \& Lauriat, A. (1984). Is homelessness a mental health problem? American Journal of Psychiatry, 141, 1546-1550.

Bohanon, C. (1991). The economic correlates of homelessness in sixty cities. Social Science Quarterly, 72 , $817-825$.

Burt, M. R. (1991). Causes of the growth of homelessness during the 1980s. Housing Policy Debate, 2, 903-936.

Burt, M. R. (1993). Over the edge: The growth of homelessness in the 1980s. New York: Russell Sage Foundation.

Burt, M. R. (2001). Helping America's homeless: Emergency housing or affordable housing? Washington, DC: The Urban Institute.

Burt, M. R., \& Cohen, B. E. (1989). Differences among homeless single women, women with children, and single men. Social Problems, 36, 508-524.

Calsyn, R. J., \& Roades, L. A. (1994). Predictors of past and current homelessness. Journal of Community Psychology, 22, 272-278.

Chen, M. H., \& Shao, Q. M. (1999). Monte Carlo estimation of Bayesian credible and HPD intervals. Journal of Computational and Graphical Statistics, 8, 69-92.

Culhane, D. P., \& Metraux, S. (1999). One-year rates of public shelter utilization by race/ethnicity, age, sex and poverty status for New York City (1990 and 1995) and Philadelphia (1995). Population Research and Policy Review, 18, 219-236.

Culhane, D. P., Lee, C. M., \& Wachter, S. M. (1996). Where the homeless come from: A study of the prior address distribution of families admitted to public shelters in New York City and Philadelphia. Housing Policy Debate, 7, 327-365.

Culhane, D. P., Metraux, S., Byrne, T., Stino, M., \& Bainbridge, J. (in press). The aging of contemporary homelessness. Contexts.

Curtis, M. A., Corman, H., Noonan, K., \& Reichman, N. (2011, February). Life shocks and homelessness (Working paper No. 16826). Cambridge, MA: National Bureau of Economic Research.

Early, D. W., \& Olsen, E. O. (2002). Subsidized housing, emergency shelters, and homelessness: An empirical investigation using data from the 1990 Census. Advances in Economic Analysis and Policy, 2(1), 2, 2-34.

Elliott, M., \& Krivo, L. J. (1991). Structural determinants of homelessness in the United States. Social Problems, 38, 113-131.

Grimes, P. W., \& Chressanthis, G. A. (1997). Assessing the effect of rent control on homelessness. Journal of Urban Economics, 41(1), 23-37.

Hawkins, R. L., \& Abrams, C. (2007). Disappearing acts: The social networks of formerly homeless individuals with co-occurring disorders. Social Science and Medicine, 65, 2031-2042.

Honig, M., \& Filer, R. K. (1993). Causes of intercity variation in homelessness. The American Economic Review, $83,248-255$.

Hopper, K., Jost, J., Hay, T., Welber, S., \& Haugland, G. (1997). Homelessness, severe mental illness, and the institutional circuit. Psychiatric Services, 48, 659-665.

Hudson, C. G. (1998). Estimating homeless populations through structural equation modeling. Journal of Sociology and Social Welfare, 25, 136-154. 
Hwang, S. W. (2001). Homelessness and health. Canadian Medical Association Journal, 164, 229-233.

Joint Center for Housing Studies at Harvard University. (2008). America's rental housing policy: The key to a balanced national policy. Cambridge, MA: Author.

Jones, R. E. (1983). Street people and psychiatry: An introduction. Hospital and Community Psychiatry, 34, $807-811$.

Kandel, W., \& Cromartie, J. (2004). New patterns of Hispanic settlement in rural America. Washington, DC: U.S. Department of Agriculture, Economic Research Service.

Khadduri, J. (2010). Rental subsidies: Reducing homelessness. In I. G. Ellen \& B. O'Flaherty (Eds.), How to house the homeless (pp. 59-88). New York: Russell Sage Foundation.

Koegel, P., Burnam, M. A., \& Baumohl, J. (1996). The causes of homelessness. In J. Baumohl (Ed.), Homelessness in America (pp. 24-34). Westport, CT: Oryx.

Koegel, P., Melamid, E., \& Burnam, A. (1995). Childhood risk factors for homelessness among homeless adults. American Journal of Public Health, 85, 1642-1649.

Landis, J. D., \& McClure, K. (2010). Rethinking federal housing policy. Journal of the American Planning Association, 76, 319-348.

Lee, B. A., \& Farrell, C. R. (2003). Buddy, can you spare a dime? Urban Affairs Review, 38, $299-324$.

Lee, B. A., \& Greif, M. J. (2008). Homelessness and hunger. Journal of Health and Social Behavior, 49(1), 3-19.

Lee, B. A., Price-Spratlen, T., \& Kanan, J. W. (2003). Determinants of homelessness in metropolitan areas. Journal of Urban Affairs, 25, 335-356.

Main, T. J. (1996). Analyzing evidence for the structural theory of homelessness. Journal of Urban Affairs, 18, 449-457.

Martin, E. (1992). Assessment of S-night street enumeration in the 1990 Census. Evaluation Review, 16, 418-438.

McChesney, K. Y. (1990). Family homelessness: A systemic problem. Journal of Social Issues, 46(4), 191205.

Metraux, S., Roman, C. G., \& Cho, R. (2008). Incarceration and homelessness. In D. Dennis, G. Locke, \& J. Khadduri (Eds.), Toward understanding homelessness: The 2007 National Symposium on Homelessness Research. Washington, DC: U.S. Department of Housing and Urban Development.

O'Flaherty, B. (1995). An economic theory of homelessness and housing. Journal of Housing Economics, 4(1), $13-49$.

O'Flaherty, B. (2004). Wrong person and wrong place: For homelessness, the conjunction is what matters. Journal of Housing Economics, 13(1), 1-15.

O'Flaherty, B. (2009). What shocks precipitate homelessness? (Discussion paper No. 0809-14). Retrieved from http://jagiellonia.econ.columbia.edu/bo2/research/whatrisks.pdf

Quigley, J. M. (1990). Does rent control cause homelessness? Taking the claim seriously. Journal of Policy Analysis and Management, 9(1), 89-93.

Quigley, J. M., \& Raphael, S. (2002). The economics of homelessness: The evidence from North America. European Journal of Housing Policy, 1, 323-336.

Quigley, J. M., Raphael, S., \& Smolensky, E. (2001). Homeless in America, homeless in California. Review of Economics and Statistics, 83(1), 37-51.

R Development Core Team. (2011). R: A language and environment for statistical computing, version 2.13. Vienna, Austria: R Foundation for Statistical Computing. http://www.R-project.org

Raphael, S. (2010). Housing market regulation and homelessness. In I. G. Ellen, \& B. O'Flaherty (Eds.), How to house the homeless (pp. 110-140). New York: Russell Sage Foundation.

Rosenheck, R., Bassuk, E., \& Salomon, A. (1999). Special populations of homeless Americans. In L. B. Fosburg \& D. L. Dennis (Eds.), Practical lessons: The 1998 National Symposium on Homelessness Research (pp. 2.1-2.31). Washington, DC: U.S. Department of Housing and Urban Development, U.S. Department of Health and Human Services.

Rossi, P. H. (1989). Down and out in America: The origins of homelessness. Chicago: University of Chicago Press.

Shinn, M., Weitzman, B. C., Stojanovic, D., Knickman, J. R., Jimenez, L., Duchon, L., James, S., \& Krantz, D. H. (1998). Predictors of homelessness among families in New York City: From shelter request to housing stability. American Journal of Public Health, 88, 1651-1657.

Stern, M. J. (1984). The emergence of the homeless as a public problem. The Social Service Review, 58, 291-301. 
Susser, E. S., Lin, S. P., \& Conover, S. A. (1991). Risk factors for homelessness among patients admitted to a state mental hospital. American Journal of Psychiatry, 148, 1659-1664.

Troutman, W. H., Jackson, J. D., \& Ekelund, R. B. (1999). Public policy, perverse incentives, and the homeless problem. Public Choice, 98, 195-212.

Tucker, W. (1987). Where do the homeless come from? National Review, 25, 32-43.

Tucker, W. (1989). America's homeless: Victims of rent control. Washington, DC: The Heritage Foundation.

U.S. Bureau of the Census. (1990). Standard Tape File 2C (STF-2C).

U.S. Department of Agriculture (USDA). (2003). Measuring rurality. Retrieved from http://www. ers.usda.gov/Briefing/Rurality/

U.S. Department of Housing and Urban Development (HUD). (1984). A report to the Secretary on the homeless and emergency shelters. Washington, DC: U.S. Government Printing Office.

U.S. Department of Housing and Urban Development (HUD). (2008). A guide to counting unsheltered homeless people. Washington, DC: Author.

U.S. Department of Housing and Urban Development (HUD). (2011). The 2010 Annual Homeless Assessment Report to Congress. Washington, DC: Author.

U.S. General Accounting Office (GAO). (1991). 1990 Census: Limitations in methods and procedures to include the homeless. Washington, DC: Author.

Wolitski, R. J., Kidder, D. P., \& Fenton, K. A. (2007). HIV, homelessness, and public health: Critical issues and a call for increased action. AIDS and Behavior, 11, 167-171.

Wright, J. D., \& Lam, J. A. (1987). Homelessness and the low-income housing supply. Social Policy, 17(4), 48-53.

Zerger, S. (2002). A preliminary review of literature: Chronic medical illness and homelessness. Nashville, TN: National Health Care for the Homeless Council. 